\title{
Coulisses
}

Revue de théâtre

19 | Hiver 1999

Varia

\section{La construction du théâtre de Montbéliard}

\section{Patrick Boisnard}

\section{OpenEdition}

\section{Journals}

Édition électronique

URL : https://journals.openedition.org/coulisses/5499

DOI : $10.4000 /$ coulisses.5499

ISSN : 2546-9460

\section{Éditeur}

Presses universitaires de Franche-Comté

\section{Édition imprimée}

Date de publication : 1 janvier 1999

Pagination : 23-24

ISBN : 2-913322-09-3

ISSN : 1150-594X

\section{Référence électronique}

Patrick Boisnard, «La construction du théâtre de Montbéliard », Coulisses [En ligne], 19 | Hiver 1999, mis en ligne le 18 octobre 2019, consulté le 07 janvier 2022. URL : http://journals.openedition.org/ coulisses/5499; DOI : https://doi.org/10.4000/coulisses.5499

Ce document a été généré automatiquement le 7 janvier 2022

Coulisses 


\title{
La construction du théâtre de Montbéliard
}

\author{
Patrick Boisnard
}

1 Dès 1827, une salle de spectacle, que l'on destinait aussi à accueillir banquets et autres réunions publiques avait été installée à Montbéliard, au premier étage de l'aile est des halles. Les travaux avaient été financés par des fonds privés, réunis dans le cadre d'une " société d'amateurs » créée à cet effet. Cette première salle, cédée par la suite à la ville, parut rapidement insuffisante.

2 Une souscription publique fut alors organisée, et l'architecte de la ville, Morel, présenta en novembre 1853 des plans pour une salle de bals, de concerts et de réunions. Malgré la perspective d'un don important promis par un couple de Montbéliardais, l'absence de subvention de l'Etat fit échouer le projet.

3 L'idée fut pourtant reprise peu de temps après. Auguste Goguel, membre de la commission de souscription et ancien élève de l'école polytechnique, produisit de nouveaux plans. Le devis, daté du 28 décembre 1854, explicite l'intention des souscripteurs de créer " une salle de concerts, tout en désirant vivement qu'elle fût en même temps salle de spectacle, si les ressources devenaient suffisantes pour remplir un double objet. » Il poursuit : " De plus, il faut que par une transformation facile à opérer, elle devienne à l'occasion une salle de bal ou de banquet, et qu'on puisse commodément y faire la distribution des prix de nos écoles ou y tenir toute autre réunion d'intérêt général. " ${ }^{1}$

4 L'emplacement choisi pour cette salle plurifonctionnelle était la cour de l'hôtel de ville, qui s'étendait à l'arrière du bâtiment. Ce parti d'implantation réunissait plusieurs avantages. Situé au centre de la ville, le nouveau théâtre, adossé à l'avant-corps central de la façade arrière de l'hôtel de ville, ne pourrait en effet que tirer profit de la qualité architecturale de ce bel édifice construit en 1776 sur les plans de l'architecte Philippe de La Guépière - plus particulièrement de son entrée majestueuse, de son vestibule et de la première volée de l'escalier qu'il lui emprunterait-, tout en autorisant une architecture sans recherche pour les façades extérieures qui resteraient peu visibles de 
la voie publique, et où par conséquent il n'y aurait pas «à se préoccuper ni de proportion ni d'ornementation extérieure $»^{2}$.

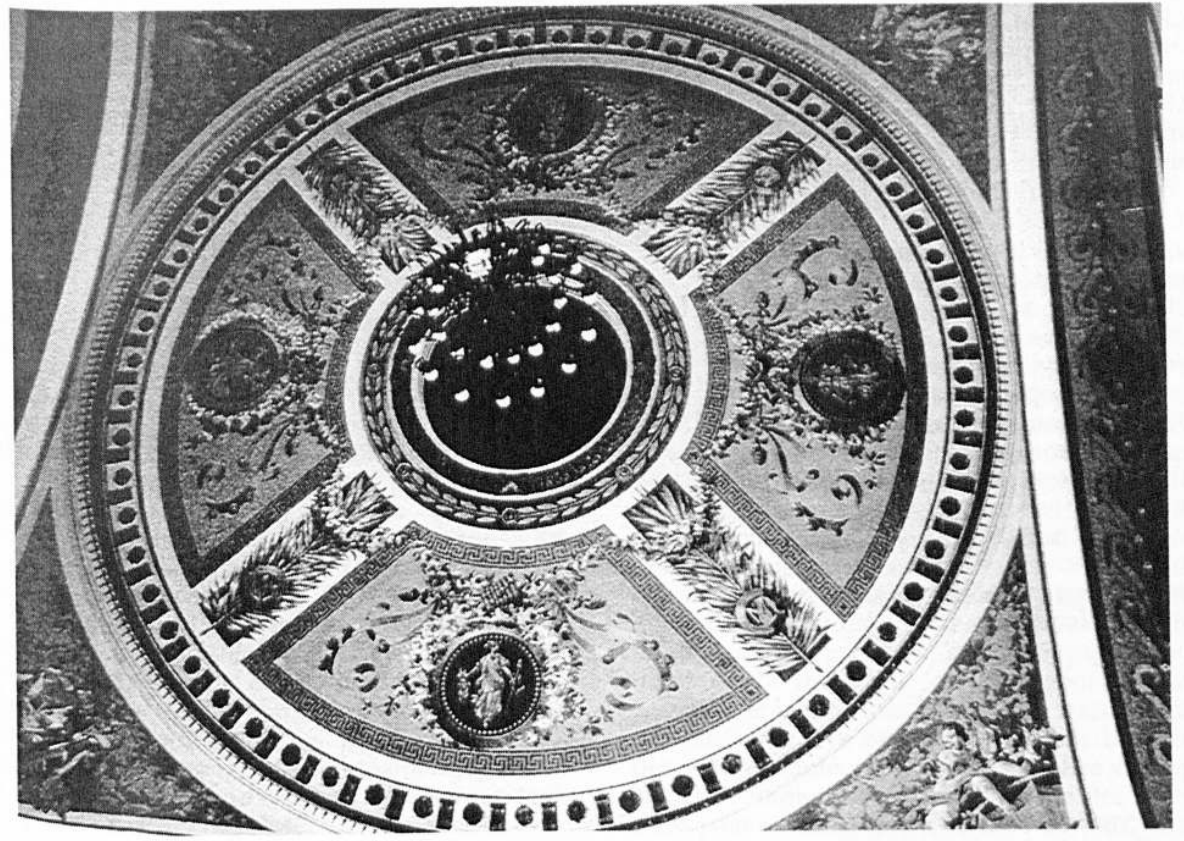

Photo $\mathrm{CRMH}$

5 Les travaux furent confiés à Théodore Flamand, architecte, et surveillés par Auguste et Ferdinand Jolidon. Leur réception définitive eut lieu le 10 avril 1859. Ils coûtèrent plus de cinquante-sept mille francs, couverts par un don, deux souscriptions publiques et une participation complémentaire de la ville.

Le plan allongé de l'édifice se signale par des ressauts qui traduisent la disposition intérieure: le vestibule adossé à l'hôtel de ville s'élargit vers la salle de spectacle, poursuivie par la scène, plus large encore. A l'intérieur, la salle, de plan en fer à cheval, est cantonnée côté scène par des pilastres corinthiens cannelés et rudentés. Côté vestibule, ces pilastres ne se retrouvent qu'au dernier niveau de balcon. Ils reçoivent les arcs qui supportent le plafond sur pendentifs. Les galeries des balcons, côté salle, portées par des poteaux en bois, ont été transformées et agrandies vers la scène en 1935.

7 La plurifonctionnalité voulue dans le programme de l'édifice a été rendue possible par un système d'estrades amovibles en bois qui permettait la transformation du parterre d'une salle de théâtre à l'italienne en une vaste salle, s'étendant du vestibule au milieu de la scène. Par ailleurs, la variante du projet effectivement réalisée permettait un éclairage diurne de la salle grâce à de larges baies percées sous le plafond circulaire, baies couvertes d'arcs surbaissés et obturables à volonté au moyen d'écrans de feutrine. L'ensemble de la machinerie fut commandée dans un deuxième temps, en décembre 1859, à plusieurs entrepreneurs locaux, charpentiers, cordiers et tourneurs.

8 Comme la plupart des théâtres de cette époque dans la région, l'attention portée à la réalisation du décor de la salle mérite d'être soulignée. On a fait appel à des peintres 
décorateurs parisiens à la solide réputation, Charles-Antoine Cambon et JosephFrançois-Désiré Thierry, pour orner le plafond de la salle, ses pendentifs, les arcs doubleaux et les galeries. Le premier, Cambon (1802-1875) a notamment travaillé aux décors du cirque olympique, des grands théâtres de Lyon et de Brest, de l'opéra de Madrid. Le second, Thierry (1812-1866) est connu pour ses travaux de décorateur d'opéras. A Montbéliard, porté par des pendentifs où jouent des putti, le plafond circulaire est divisé en quartiers bordés de grecques, séparés par des palmes frappées du monogramme de la ville $(\mathrm{M})$, qui représentent, dans des médaillons entourés de guirlandes de fleurs, les Muses. Jusqu'à la restauration intérieure de 1986, les gardecorps des balcons conservaient leur décor d'origine formé de postes et de motifs végétaux sur fond vert.

Le théâtre de Montbéliard

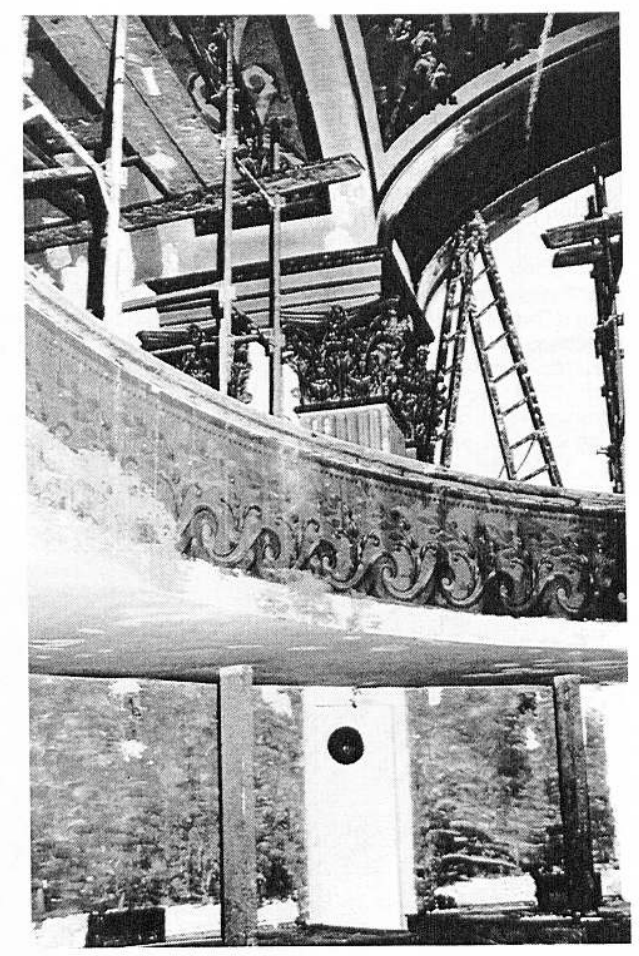

Photo CRMH

\section{NOTES}

1. Projet d'une salle de spectacle..., devis par Auguste Goguel, Archives municipales de Montbéliard, 9 M 48 bis.

2. Ibid. 


\section{AUTEUR}

\section{PATRICK BOISNARD}

Chargé de la protection des monuments historiques - DRAC de Franche-Comté 